\title{
Assessment of GFP fluorescence in cells of Streptococcus gordonii under conditions of low pH and low oxygen concentration
}

\author{
Martin C. Hansen, ${ }^{1}$ Robert J. Palmer, $\mathrm{Jr}^{2}{ }^{2}+$ Camilla Udsen, ${ }^{1}$ \\ David C. White ${ }^{2}$ and Søren Molin ${ }^{1}$
}

Author for correspondence: Søren Molin. Tel: +45 4525 2513. Fax: +45 45887328.

e-mail: soeren.molin@biocentrum.dtu.dk

1 Molecular Microbial Ecology Group, Department of Microbiology, Technical University of Denmark, Building 301, DK-2800 Lyngby, Denmark

2 Biofilm Imaging Facility, Center for Environmental Biotechnology, University of Tennessee, Knoxville, TN 37932-2575, USA

\begin{abstract}
Use of green fluorescent protein (GFP) as a molecular reporter is restricted by several environmental factors, such as its requirement for oxygen in the development of the fluorophore, and its poor fluorescence at low $\mathrm{pH}$. There are conflicting data on these limitations, however, and systematic studies to assess the importance of these factors for growing bacterial cultures are lacking. In the present study, homogeneous expression of the gfpmut3* gene directed by a synthetic constitutive lactococcal promoter was demonstrated in batch cultures and in biofilms of Streptococcus gordonii DL1. A lower limit of oxygen concentration for maturation of the GFP fluorophore was determined: fluorescence was emitted at 0.1 p.p.m. dissolved oxygen (in conventionally prepared anaerobic media lacking reducing agents), whereas no fluorescence was detected in the presence of 0.025 p.p.m. dissolved oxygen (obtained by addition of L-cysteine as reducing agent). When an anaerobically grown (nonfluorescent) $>\mathbf{5 0} \mu \mathrm{m}$ thick biofilm was shifted to aerobic conditions, fluorescence could be detected within $\mathbf{4}$ min, reaching a maximum over the next $16 \mathrm{~min}$. It was not possible to detect any fluorescence gradients (lateral or vertical) within the $>\mathbf{5 0} \boldsymbol{\mu m}$ thick biofilm, and fluorescence development after the shift to aerobic conditions occurred throughout the biofilm (even at the substratum). This suggests that oxygen gradients, which might result in reduced GFP fluorescence, did not exist in the $>\mathbf{5 0} \boldsymbol{\mu m}$ thick biofilm of this organism. Production of lactic acid and the subsequent acidification in batch cultures of S. gordonii DL1 led to a decrease in fluorescence intensity. However, severe $\mathrm{pH}$ reduction was prevented when the bacterium was grown as a biofilm in a flowcell, and a homogeneous distribution of a strong fluorescence signal was observed. These findings show that GFP can be applied to studies of oxygen-tolerant anaerobic bacteria, that densely packed, flowcellgrown biofilms of $S$. gordonii do not develop oxygen gradients inhibitory to GFP fluorescence development, and that the often transient nature of GFP fluorescence in acid-producing bacteria can be overcome in flowcells, probably by the elimination of metabolic by-product accumulation.
\end{abstract}

Keywords: Gram-positive bacteria, biofilms, green fluorescent protein tagging, anaerobic growth

†Present address: National Institute for Dental Craniofacial Research, NIH Oral Infection and Immunity Branch, Bldg 30, 30 Convent Drive, Bethesda, MD 20892, USA.

Abbreviation: GFP, green fluorescent protein. 


\section{INTRODUCTION}

Green fluorescent protein, GFP, has been widely used for clonal tagging or as a reporter for specific gene expression in both bacteria and higher organisms. Autocatalytic formation of the fluorophore in the polypeptide chain, along with the advantages of fluorescence in advanced microscopy and image analysis, have driven the rapid development of in situ methods for investigations of cellular activity in complex scenarios such as mixed-species biofilm communities. In microbiology, by far the greatest impact of GFP has been in studies of Gram-negative bacteria, partly due to the availability of a broad range of expression systems derived from these bacteria, and partly because the majority of in situ studies so far have been concerned with Proteobacteria. Fewer reports have described the applications of GFP to analyses of Gram-positive bacterial (e.g. Bubert et al., 1999; Fernández de Palencia et al., 2000; Freitag \& Jacobs, 1999; Geoffroy et al., 2000; Lewis \& Errington, 1996; Lewis \& Marston, 1999; Scott et al., 1998).

The GFP fluorophore has been characterized in detail. It consists of a $p$-hydroxybenzylideneimidazolinone formed autocatalytically by cyclization and oxidation of the Ser-Tyr-Gly sequence at positions $65-67$ with a time constant of approximately $2-4 \mathrm{~h}$ at $22^{\circ} \mathrm{C}$ and atmospheric $\mathrm{pO}_{2}$ (Heim et al., 1994, 1995). The final step in protein maturation is dehydrogenation by molecular oxygen of residue 66 (Cubitt et al., 1995; Heim et al., 1994; Reid \& Flynn, 1997). In order to enhance the fluorescence of GFP, to broaden the useful $\mathrm{pH}$ and temperature ranges of the protein, to increase the rate of fluorophore formation, and to shift wavelengths of excitation and emission, several mutations of the protein have been introduced (Cormack et al., 1996; Crameri et al., 1996; Delagrave et al., 1995; Ehrig et al., 1995; Elsliger et al., 1999; Heim et al., 1994; Heim \& Tsien, 1996; Kimata et al., 1997; Patterson et al., 1997; Siemering et al., 1996; Ward, 1998). One variant (Gfpmut3b) with two mutations in the chromophore region (S65G, S72A) fluoresces 21 times more intensely than wtGfp, and was observed to mature with a time constant of approximately $45 \mathrm{~min}$ (Cormack et al., 1996). Throughout the present study, a variant of this protein (Gfpmut3*) was used, which has an additional mutation at position $2(\mathrm{~S} 2 \mathrm{R})$ that permits introduction of a SphI site in the gene (Andersen et al., 1998).

Many Gram-positive bacteria, which are interesting in relation to industrial applications or as human and animal pathogens, are fermentative and microaerophilic. It has generally been assumed that GFP was less useful as a reporter in these organisms because of the requirement for oxygen in fluorophore formation (Cody et al., 1993; Cubitt et al., 1995 ; Heim et al., 1994; Prasher et al., 1992; Reid \& Flynn, 1997). In addition, there are fewer handy genetic tools available for Gram-positive bacteria compared to those designed for enterics and other Proteobacteria. It is therefore understandable that the current literature concerning GFP as a reporter in, for example, streptococci and related bacteria is quite limited. Besides the oxygen requirements, the actual rate of oxidation, and the stability of GFP under different conditions, are uncertain (Cormack et al., 1996; Heim et al., 1994; Reid \& Flynn, 1997). The design of standardized GFP test plasmids (a broad-host-range shuttle vector carrying the $g f p$ gene under control of a strong constitutive promoter) and clarification of the limitations of the specific growth conditions of these organisms in relation to obtainable fluorescence signals are therefore warranted.

The Gram-positive Streptococcus gordonii is one of many bacterial species involved in the formation of dental plaque. In the oral environment, S. gordonii is an initial colonizer, which grows attached to the tooth surface (Kolenbrander \& London, 1993). It is important to characterize the general performance of this bacterium when growing in biofilms in addition to what has been investigated for cells in the planktonic state, since sessile populations represent in vivo conditions more accurately than planktonic bacteria. Cultivation of bacteria in flow-chambers makes it possible to study biofilm communities, and this model system approach has proven to be much more representative of conditions in the oral cavity than are static systems (Palmer \& Caldwell, 1995).

The aims of this study were (i) to design and characterize genetic tools targeting Gram-positive bacteria in general and microaerophilic species in particular; (ii) to test the limits of the use of GFP as a marker under suboptimal maturation conditions (low $\mathrm{pH}$, low $\mathrm{O}_{2}$ ), and thereby to address these limitations in a practical application of GFP - the use of the gfpmut3* gene (Andersen et al., 1998) as a molecular marker in the Gram-positive bacterium S. gordonii DL1 grown in batch cultures and in biofilms under aerobic and anaerobic conditions; and (iii) to determine which growth conditions allow sufficient GFP reporter signals to be useful in connection with in vitro as well as in situ studies.

\section{METHODS}

Bacterial strains and growth conditions. Bacterial strains and plasmids are listed in Table 1. S. gordonii DL1 (kindly donated by P. Kolenbrander, NIDCR/NIH) was grown at $34^{\circ} \mathrm{C}$ in CAMG broth (per litre: $5 \mathrm{~g}$ tryptone, $5 \mathrm{~g}$ yeast extract, $5 \mathrm{~g}$ dibasic potassium phosphate) supplemented with either $2 \mathrm{~g}$ or $5 \mathrm{~g}$ glucose, as batch cultures in anaerobic culture tubes (Bellco Labs). The medium was prepared using strict anaerobic methods (boiling under sparging with 95:5 $\mathrm{N}_{2} / \mathrm{CO}_{2}$ for $1 \mathrm{~h}$ prior to tubing, head-gas replacement and autoclaving). Resazurin $(0 \cdot 1 \%, \mathrm{w} / \mathrm{v}$, stock solution) was added to a final concentration of $0.0001 \%$ as an $E_{\mathrm{h}}$ (redox potential) indicator and visual check of reduced conditions. Growth medium for the biofilms was either a $1 / 10$ diluted version of anaerobic CAMG broth (per litre: $0.5 \mathrm{~g}$ tryptone, $0.5 \mathrm{~g}$ yeast extract, $5 \mathrm{~g}$ dibasic potassium phosphate, $0 \cdot 2 \mathrm{~g}$ glucose), or $1 / 10$ diluted 
Table 1. Strains and plasmids

\begin{tabular}{|c|c|c|}
\hline Strain or plasmid & Description $†$ & Reference or source \\
\hline \multicolumn{3}{|l|}{ Strains } \\
\hline E. coli JM105 & $\begin{array}{l}\text { thi rpsL }\left(\mathrm{Str}^{\mathrm{r}}\right) \text { end A sbcB15 sbcC hsdR4 } \\
\left(\mathrm{r}_{\mathrm{k}}^{-} \mathrm{m}_{\mathrm{k}}^{-}\right) \Delta(\text { lac-proAB })\left[\mathrm{F}^{\prime} \text { traD36 lacl }\right. \\
\left.\Delta(\text { lacZ }) M 15 \text { pro } A^{+} B^{+}\right]\end{array}$ & $\begin{array}{l}\text { Yanisch-Perron et al. } \\
\text { (1985) }\end{array}$ \\
\hline S. gordonii DL1 & & $\begin{array}{l}\text { P. Kolenbrander } \\
\text { (NIDCR/NIH) }\end{array}$ \\
\hline \multicolumn{3}{|l|}{ Plasmids } \\
\hline pJBA25 & $\mathrm{Ap}^{\mathrm{R}} ;$ pUC18Not-RBSII-gfpmut $3 *-\mathrm{T}_{0}-\mathrm{T}_{1}$ & Andersen et al. (1998) \\
\hline pCP25 & $\mathrm{Em}^{\mathrm{R}} ; \mathrm{pAK} 80-\mathrm{P}_{\mathrm{CP} 25}$ & Jensen \& Hammer (1998) \\
\hline pTRKL2 & $\mathrm{Em}^{\mathrm{R}} ;$ lacZ oriP15A oripAM $\beta 1$ & $\begin{array}{l}\text { O'Sullivan \& } \\
\text { Klaenhammer (1993) }\end{array}$ \\
\hline pCM18 & $\mathrm{Em}^{\mathrm{R}} ;$ pTRKL2-P ${ }_{\mathrm{CP} 25}-\mathrm{RBSII}-g f p$ mut $3 *-\mathrm{T}_{0}-\mathrm{T}_{1}$ & This study \\
\hline
\end{tabular}

$\dagger \mathrm{Ap}^{\mathrm{R}}$, ampicillin resistance; $\mathrm{Em}^{\mathrm{R}}$, erythromycin resistance; RBSII, synthetic ribosome-binding site; $\mathrm{T}_{0}-\mathrm{T}_{1}$, transcriptional terminators from phage lambda and from the $r r n B$ operon of E. coli.

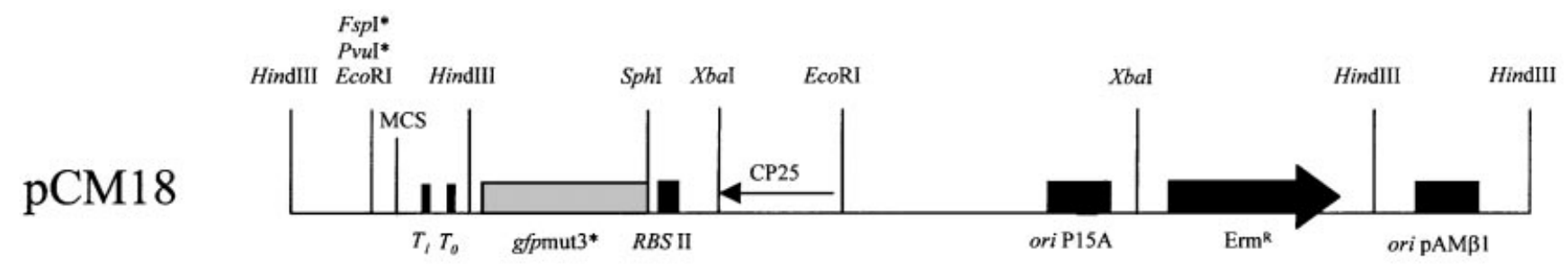

Fig. 1. Genetic and physical map of the pCM18 plasmid vector (not to scale). Only relevant restriction sites are indicated (sites marked * are unique). Abbreviations: MCS, multiple cloning site (EcoRI, Smal*, Sall*, Hindlll, Nrul*, Xbal); T1, transcriptional terminator from the $r r n B$ operon of $E$. coli; $T_{0}$, transcriptional terminator from phage lambda; $g f p m u t 3 *$, gene encoding Gfpmut3* (S2R, S65G, S72A); RBSII, synthetic ribosome-binding site; CP25, synthetic constitutive lactococcal promoter; ori, origin of replication; $\mathrm{Erm}^{\mathrm{R}}$, erythromycin resistance gene.

anaerobic CAMG broth supplemented with $0 \cdot 5 \mathrm{~g} \mathrm{~L}$-cysteine $\mathrm{l}^{-1}$ as a reducing agent. Erythromycin $\left(5 \mathrm{mg} \mathrm{ml}^{-1}\right)$ was added to a final concentration of $5 \mu \mathrm{g} \mathrm{ml}^{-1}$ in the medium, in the experiments where a selection pressure for the maintenance of plasmid pCM18 was applied. Growth medium for the transformation of $S$. gordonii DL1 was Todd-Hewitt broth (Difco) supplemented with $5 \%(\mathrm{v} / \mathrm{v})$ heat-inactivated horse serum. Escherichia coli JM105(pCM18) was maintained at $37^{\circ} \mathrm{C}$ in LB broth containing $4 \mathrm{~g} \mathrm{NaCl} \mathrm{l}^{-1}$ and supplemented with erythromycin to a final concentration of $150 \mu \mathrm{g} \mathrm{ml}^{-1}$.

Plasmid construction and transformation of S. gordonii. The synthetic constitutive lactococcal promoter, CP25 (Jensen \& Hammer, 1998), was excised from plasmid pCP25 with XbaI and ligated into XbaI-digested pJBA25 (Andersen et al., 1998) upstream of the promoter-less $g f p$ mut $3 *$. The fragment from this new plasmid containing CP25, the synthetic ribosomebinding site (RBSII), the $g f p$ mut $3 *$ gene and two terminators (the transcriptional terminator $T_{0}$ from phage lambda and the transcriptional terminator $\mathrm{T}_{1}$ from the $r r n B$ operon of $E$. coli) was excised with XhoI and NotI, made blunt ended, and ligated into the unique EcoRV site of the vector pTRKL2 (O’Sullivan \& Klaenhammer, 1993). The construct was verified by agarose gel electrophoresis of analytical digestions. A linearized form of the plasmid pCM18 is shown in Fig. 1.
The transformation procedure was essentially as described by Perry et al. (1983). The plasmid pCM18 was purified from $2 \mathrm{ml}$ of an overnight culture of E. coli JM105(pCM18) using the QIAprep Spin Miniprep Kit (QIAGEN) and eluted in $200 \mu \mathrm{H} \mathrm{H}_{2} \mathrm{O}$. An overnight culture of $S$. gordonii DL1 grown in Todd-Hewitt broth supplemented with $5 \%(\mathrm{v} / \mathrm{v})$ heatinactivated horse serum was diluted 100 -fold and incubated for $3.5 \mathrm{~h}$ at $34^{\circ} \mathrm{C}$. Sixty-four microlitres of the culture was mixed with $32 \mu$ of the plasmid preparation and incubated for $1 \cdot 5 \mathrm{~h}$. The cells were spread on Todd-Hewitt agar plates containing $5 \mu \mathrm{g}$ erythromycin $\mathrm{ml}^{-1}$, and transformants were scored after $2 \mathrm{~d}$ incubation at $34^{\circ} \mathrm{C}$.

Flowcell system. $S$. gordonii DL1 was grown as biofilms in glass flowcells (channel dimensions $3 \mathrm{~mm}$ wide and $1 \mathrm{~mm}$ high) for microscopy (Palmer \& Caldwell, 1995). Medium for the flowcells was supplied from a reservoir through silicone tubing. A peristaltic pump (Watson Marlow set at rate $12 \mathrm{ml}$ $\mathrm{h}^{-1}$ ) pulled medium through the system and led the effluent to a waste container.

Glove bag. In order to obtain anaerobic conditions for the flowcells, an Inflatable Glove Bag (model X-17-17, Instruments for Research and Industry, Cheltenham, PA, USA) was used to 
contain the experimental set-up (Hansen et al., 2000). The gas environment in the glove bag was 95:5 $\mathrm{N}_{2} / \mathrm{CO}_{2}$.

Measurement of optical density. A Shimadzu spectrophotometer model UV-1201 (SpectraChrom, Brøndby, Denmark), was used for measurements of $\mathrm{OD}_{600}$.

Measurement of pH. A Sentron pH meter model 1001 was used for measurements of $\mathrm{pH}$. Calibration was performed using $\mathrm{pH} 4 \cdot 0$ and $\mathrm{pH} 7 \cdot 0$ buffers.

Measurement of dissolved oxygen. The concentration of dissolved oxygen in the anaerobic medium in anaerobic culture tubes (Bellco) and in the reduced flowcell medium was determined colorimetrically using CHEMets Dissolved Oxygen Ampoules (CHEMetrics, Calverton, VA, USA). All measurements were done in the glove bag. Tubed anaerobic medium without L-cysteine contained $0 \cdot 1$ p.p.m. dissolved oxygen. Medium with L-cysteine for the flowcells contained $\leqslant 0.025$ p.p.m. dissolved oxygen (limit of detection).

Scanning confocal laser microscopy. Flowcells were removed from the glove bag prior to microscopic examination. In the shift experiment from anaerobic to aerobic medium, the medium supply was changed as soon as the flowcell was removed from the glove bag, and the biofilms were immediately observed using a Leica TCS-NT confocal laser microscope. The microscope settings were as follows: excitation at $488 \mathrm{~nm}$, emission at 530/30 BP into channel 1 to record GFP fluorescence, $100 \times 1.4 \mathrm{NA}$ oil-immersion lens at an Airy disc setting of $0 \cdot 9,1 \mu \mathrm{m}$ steps collected with four frames averaged at each step. When an increase in fluorescence intensity was expected, the PMT gain was deliberately reduced in order to be able to keep this setting throughout the entire experiment and still avoid saturation in the brightest images. Biofilms were also subjected to microscopic examination after $18 \mathrm{~h}$ and after $2 \mathrm{~d}$ of growth.

Epifluorescence microscopy. Fluorescence in suspended cells from liquid cultures was observed by applying $4 \mu \mathrm{l}$ of culture on a microscope slide followed by examination using either the confocal laser microscope as described or a Carl Zeiss Axioplan epifluorescence microscope. For the latter, the excitation source was a $100 \mathrm{~W}$ HBO bulb, and digital images were captured with a 12-bit cooled slow-scan charge-coupleddevice camera (KAF 1400 chip; Photometrics). The chargecoupled-device camera was controlled by the PMIS software (Photometrics), and an FITC filter set was used for the excitation and detection of GFP.

\section{RESULTS AND DISCUSSION}

\section{Construction and characterization of pCM18 - a broad-host-range GFP test plasmid}

Plasmid pCM18 carries a fusion between the synthetic strong lactococcal constitutive promoter CP25 (Jensen \& Hammer, 1998) and the gfpmut3* gene (see Fig. 1). It is a low-copy-number (6-9 per chromosome equivalent) broad-host-range plasmid, which is easily introduced and maintained in a variety of bacteria due to its relatively small size $(8.2 \mathrm{~kb}$ including the $1.8 \mathrm{~kb}$ gfpmut3* gene insert) and the presence of $\mathrm{pAM} \beta 1$
(Gram-positive) and P15A (Gram-negative enterics) replicons. Expression of the gfpmut3* gene from pCM18 yielded green fluorescence in both $S$. gordonii DL1 and E. coli JM105. The CP25-gfpmut3* fusion was also introduced into Bacillus subtilis and Lactococcus lactis, yielding green fluorescence in both organisms (unpublished results). The gene dosage carried by the low-copy-number plasmid pCM18 was expected to be relatively constant, in contrast to many high-copy-number plasmids, due to a reduced probability of adverse effects on cellular growth caused by excess heterologous gene expression. Furthermore, pCM18 was predicted to be segregationally stable due to the replication mechanism of the pAM $\beta 1$ replicon, which proceeds by the theta $(\Theta)$ mechanism in Gram-positive bacteria, and therefore does not lead to accumulation of single-stranded intermediates as in replication by the rolling-circle replication mechanism (Ehrlich et al., 1991). This was confirmed in growth experiments in batch cultures, in which no decrease in fluorescence was observed in a culture growing for ten generations in the absence of selection pressure. Parallel growth experiments were performed, in which biofilms were grown without selection pressure to monitor loss of the plasmid. Biofilms were grown in the absence or presence of $5 \mu \mathrm{g}$ erythromycin $\mathrm{ml}^{-1}$. It was found that fluorescence was homogeneously distributed in both types of biofilms, and that the pattern of biofilm development was the same (data not shown). This implies that pCM18 can be used as a reliable vehicle for single-cell reporters under a variety of growth conditions, and furthermore that the construct provides an easy way of introducing the CP25-gfpmut3* fusion into a variety of Gram-negative and Gram-positive bacteria.

\section{Expression of GFP in batch cultures of S. gordonii DL1(pCM18)}

The CAMG broth medium used for growth of $S$. gordonii DL1 was prepared either anaerobically or aerobically. The conventionally prepared anaerobic medium contained $0 \cdot 1$ p.p.m. $\left(0 \cdot 1 \mathrm{mg} \mathrm{l} \mathrm{l}^{-1}\right.$, approximately $3 \mu \mathrm{M})$ dissolved oxygen. There have been several reports on the oxygen requirements of GFP for the final oxidation of the mature, cyclized chromophore (Cody et al., 1993; Heim et al., 1994, 1995; Inouye \& Tsuji, 1994; Prasher et al., 1992), and describing the kinetics of the steps involved in chromophore formation including the final oxidation of the tripeptide (Reid \& Flynn, 1997). We found that exponentially growing cells were fluorescent in anaerobic medium, i.e. in the presence of $0 \cdot 1$ p.p.m. dissolved oxygen, even after several transfers to secure sufficient dilution of the initial inoculum (data not shown). This implies that a significant proportion of GFP was oxidized by the trace amounts of oxygen found in our anaerobic pressure tubes. Several applications of GFP have faced troublesome interpretations of the fluorescence due to potentially limiting concentrations of oxygen, e.g. cells in the centre of microcolonies in otherwise aerobic environments. The present demon- 


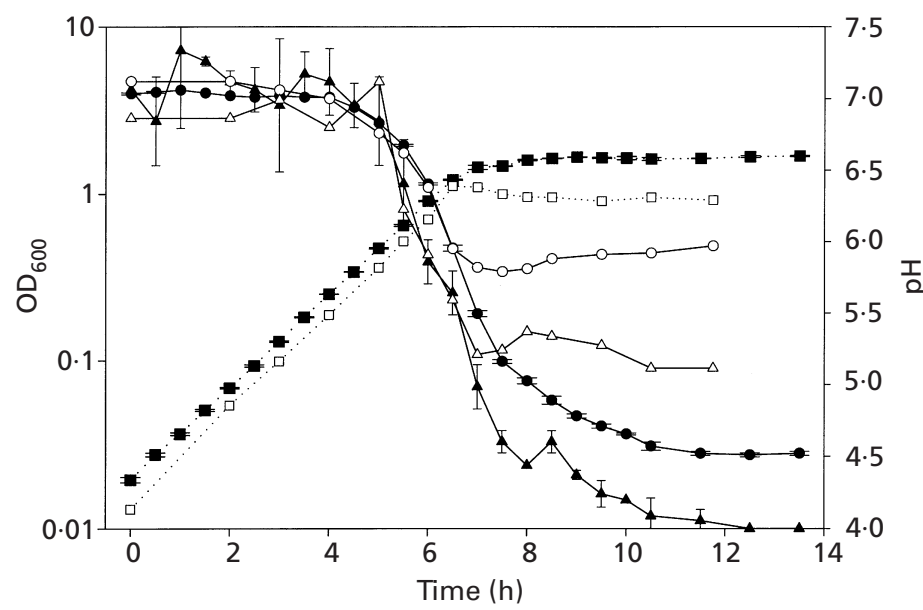

Fig. 2. Aerobically grown culture of $S$. gordonii DL1(pCM18) expressing Gfpmut3* in CAMG broth supplemented with either $0.2 \%$ glucose (open symbols) or $0.5 \%$ glucose (filled symbols). Simultaneous measurements were made of growth $\left(\mathrm{OD}_{600}\right)$ $(\square, \boldsymbol{\square}), \mathrm{pH}$ in the medium $(\bigcirc, \boldsymbol{0})$, and mean fluorescence intensity of single cells (relative mean maximum pixel intensity) $(\triangle$, A). stration that very low amounts of oxygen are needed for maturation of GFP opens the possibility of using this reporter under conditions of near-anaerobiosis.

S. gordonii is a homofermentative bacterium: glucose is fermented to twice the equimolar amount of lactate. The production of acid reduces $\mathrm{pH}$ in the medium as lactate accumulates. As shown in the initial characterization of GFP (Prasher et al., 1992), the fluorescence of the protein is significantly influenced by changes in $\mathrm{pH}$. Elsliger et al. (1999) argued that the quenching of fluorescence at low $\mathrm{pH}$ is due to the formation of a protonated form of the chromophore phenolate in the GFP S65T variant. This $\mathrm{pH}$ sensitivity of GFP was exploited by Robey et al. (1998) and Miesenböck et al. (1998), using mutants of GFP as in vivo reporters of cytoplasmic $\mathrm{pH}$. The $\mathrm{pH}$ sensitivity becomes problematic when GFP is used in lactic acid bacteria in batch cultures. For several lactic acid bacteria, it has been found that the intracellular $\mathrm{pH}$ decreased with the extracellular $\mathrm{pH}$, maintaining a constant $\Delta \mathrm{pH}$ of $0 \cdot 5-0 \cdot 8$ units (Cook \& Russell, 1994; Siegumfeldt et al., 2000). Similarly, epifluorescence microscopy of single cells from an aerobic exponentially growing culture of $S$. gordonii DL1 showed that fluorescence was equally distributed among the cells in the population. As $\mathrm{pH}$ decreased in the medium, fluorescence intensity decreased. If the growth medium is supplemented with different amounts of glucose $(0.2$ and $0.5 \%)$, the cultures reach stationary phase at different $\mathrm{pH}$ values. This makes it possible to compare the $\mathrm{pH}$ effect unbiased by the change in growth phase. In medium with $0.2 \%$ glucose, the $\mathrm{pH}$ decreased from 7 to 6 , resulting in a corresponding drop in fluorescence intensity. However, when the medium was supplemented with $0.5 \%$ glucose, the $\mathrm{pH}$ decreased to $4 \cdot 5$, with a further decrease in fluorescence. Fluorescence from cells at or below about pH 5.5 was only detectable through a strong amplification of the signal, making the fluorescence practically useless, as the cells lost edge definition (they were difficult to spot). These data are summarized in Fig. 2. For each sample point, a set of epifluorescence micrographs was obtained, and the fluorescence intensity was estimated using the maximum pixel intensity option from the PMIS (Photometrics) software. Although streptococci to some extent may control their internal pH (Cook \& Russell, 1994), Fig. 2 clearly shows the effect of external pH on GFP fluorescence in vivo. This phenotype was independent of oxygen supplied by vigorous shaking of the culture.

It was attempted to reverse the acid-induced reduction in fluorescence by shifting stationary-phase GFP-tagged cells to fresh medium or to a buffer at neutral $\mathrm{pH}$. As summarized in Table 2, it was possible to regain fluorescence from cells in stationary phase (at pH below 5) for up to $13 \mathrm{~h}$. However, it was not possible to regain fluorescence from cells after $23 \mathrm{~h}$ in stationary phase at low $\mathrm{pH}$. These results were independent of resuspension medium and incubation time, as resuspension of cells was performed in either fresh medium or a buffer at neutral $\mathrm{pH}$ for either $5 \mathrm{~min}$ or $60 \mathrm{~min}$. These findings add to a recent observation in GFP-tagged lactococci (Fernández de Palencia et al., 2000), which indicated that the acid-induced reduction of fluorescence was reversible upon resuspension in PBS buffer. Thus, GFP does not seem to be degraded upon low $\mathrm{pH}$ and starvation conditions for up to $13 \mathrm{~h}$ by induced proteases, as the fluorescence can be regained by a shift to neutral $\mathrm{pH}$. However, the prolonged stationary phase $(23 \mathrm{~h})$ of $S$. gordonii is critical, as the cells lose fluorescence permanently.

In a shift experiment from anaerobic to aerobic conditions, Scott et al. (1998) observed heterogeneous expression of GFP in colonies of L. lactis IL1403 on GM17 agar plates after $22 \mathrm{~h}$ exposure to air. Since GFP fluorescence was restricted to the outer zone of the colonies, it was argued that oxygen diffusion through the colonies was restricted. Parallel experiments with $E$. coli V850 on LB plates showed homogeneous GFP expression in the colonies, indicating that for this organism there was no diffusion barrier. However, the external $\mathrm{pH}$ on colonies of lactic acid bacteria (e.g. $L$. lactis IL1403) on a GM17 (0.5\% glucose) agar plate is approximately 5 (depending on the distribution and size of colonies) (unpublished data). This fact, together with the findings presented above, suggests that an acidifi- 
Table 2. Fluorescence in batch cultures of S. gordonii DL1(pCM18)

\begin{tabular}{|c|c|c|c|c|c|}
\hline \multirow[t]{2}{*}{ Time $(\mathbf{h}) *$} & \multirow[t]{2}{*}{ Condition } & \multirow[t]{2}{*}{$\mathrm{pH}$} & \multirow[t]{2}{*}{ Fluorescence $\dagger$} & \multicolumn{2}{|c|}{$\begin{array}{c}\text { Fluorescence } \nmid \text { after } \\
\text { resuspension } \neq\end{array}$} \\
\hline & & & & $5 \mathrm{~min}$ & $60 \mathrm{~min}$ \\
\hline-1 & no cysteine, $0 \cdot 1$ p.p.m. $\mathrm{O}_{2}$ & 7 & + & & \\
\hline-1 & with cysteine, $\leqslant 0 \cdot 025$ p.p.m. $\mathrm{O}_{2}$ & 7 & - & & \\
\hline-1 & aerobic & 7 & + & & \\
\hline 0 & aerobic & 6 & + & & \\
\hline 5 & aerobic & $4 \cdot 5$ & - & + & + \\
\hline 13 & aerobic & $4 \cdot 5$ & - & + & + \\
\hline 23 & aerobic & $4 \cdot 5$ & - & - & - \\
\hline
\end{tabular}

* Time after entry into stationary phase.

$\dagger+$, Fluorescence; - , absence of fluorescence.

$\ddagger$ Cells were resuspended in either fresh growth medium or phosphate buffer $\mathrm{pH} 7 \cdot 0$; fluorescence was determined 5 or $60 \mathrm{~min}$ after resuspension.

cation of the medium rather than oxygen limitation in the L. lactis IL1403 colonies is the primary cause of fluorescence reduction. This explanation is in agreement with our demonstration that maturation of GFP still occurs at very low levels of oxygen, and with the fact that no oxygen consumption occurs in colonies of $L$. lactis.

\section{Expression of GFP in biofilms}

As in batch cultures, green fluorescence in biofilms was observed in medium containing approximately $0 \cdot 1$ p.p.m. oxygen. The $\mathrm{pH}$ in the effluent from a biofilm grown for $2 \mathrm{~d}$ was approximately 7 (data not shown). GFP fluorescence in aerobic biofilms of $S$. gordonii DL1(pCM18) was homogeneously distributed throughout the biofilm until a very thick cell-layer $(>50 \mu \mathrm{m})$ quenched the fluorescence signal. The continuous flow of medium through the flowcell system prevents accumulation of lactic acid and a resultant drop in $\mathrm{pH}$, and consequently the GFP fluorescence signal intensity allowed excellent recordings of the cells by scanning confocal laser microscopy throughout the course of the biofilm development (up to $4 \mathrm{~d}$ ).

When the entire flowcell set-up was placed in a glovebag as described by Hansen et al. (2000), and L-cysteine was added to the medium, the biofilms could be maintained under strictly anaerobic conditions $(\leqslant 0.025$ p.p.m. oxygen, equivalent to $\leqslant 0 \cdot 8 \mu \mathrm{M}$ ). Under these conditions the biofilms increased in biomass faster than parallel aerobic biofilms, but similar biofilm characteristics (distribution of biomass and cellular morphologies) were developed under the two sets of conditions. However, green fluorescence was not observed in these biofilms until after a shift to aerobic medium. Inspection of the fluorescence development in a shift from anaerobiosis to aerobiosis using the scanning confocal microscope showed that fluorescence was detectable $4 \mathrm{~min}$ after oxygen was supplied (Fig. 3). During the next $16 \mathrm{~min}$, a further increase in fluorescence intensity occurred, but after an additional 20, 40, 60 and $100 \mathrm{~min}$, little or no increase in fluorescence could be observed. In Fig. 3, single optical sections directly at the substratum show the fluorescence increase at the deepest regions of the biofilm (in the middle of microcolonies) as well as in cells exposed to pore-space fluid (cells at the edge of those microcolonies), and are displayed in conjunction with images of the entire biofilm biomass (maximum projections). These micrographs of single sections indicate the uniform increase of fluorescence in this biofilm as do the side panels ( $z x$ and $z y$ scans) on the entire stack of images. Neither vertical nor horizontal gradients of fluorescence through the biofilm were observed - fluorescence increased the same way in cells from the middle of a micro-colony as in those on the surface, indicating a rapid distribution of oxygen through the flowcell and through the $S$. gordonii biomass.

Previous determinations of the ordered reaction kinetics of the three distinct steps in the chromophore formation of purified GFP (S65T) showed that oxidation of the mature and cyclized protein had a time constant $k=$ $1.51 \times 10^{-4} \mathrm{~s}^{-1}$, corresponding to $T_{1 / 2}=76 \mathrm{~min}($ Reid \& Flynn, 1997). In an experiment where anaerobically grown E. coli cells were shifted to aerobic conditions, Heim et al. (1995) found that the S65T mutant GFP formed four times faster $\left(T_{1 / 2}=27 \mathrm{~min}\right)$ than wild-type GFP. Unfortunately, measurements of the kinetics based on the S65T GFP makes comparisons with Gfpmut3* (S2R, S65G, S72A) difficult, as certain mutations have been observed to affect the rate of chromophore formation (Cormack et al., 1996; Heim et al., 1995). The time constant measured in vivo by Heim et al. (1995), however, shows a much faster oxidation step than wildtype GFP, which corresponds to results obtained for several enhanced mutants (Cubitt et al., 1995; Reid \& Flynn, 1997; Scott et al., 1998). The in vivo examinations 
(a)

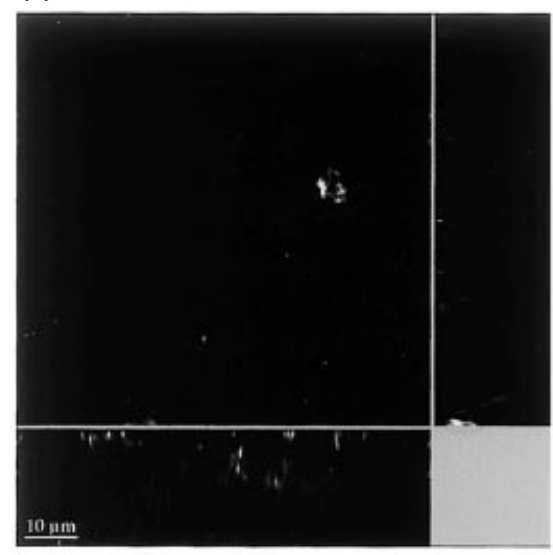

(b)

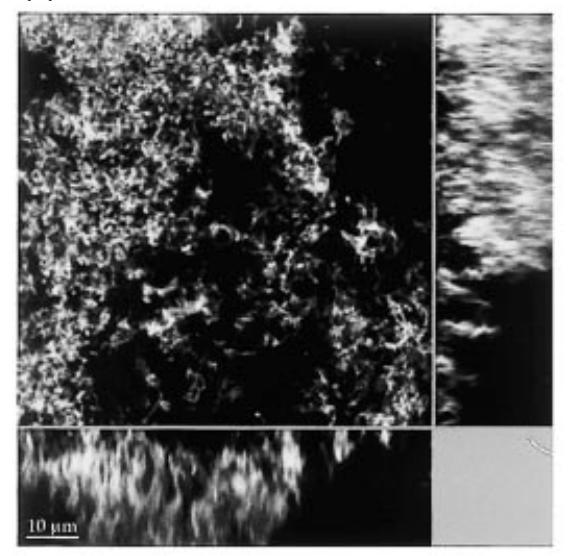

(c)

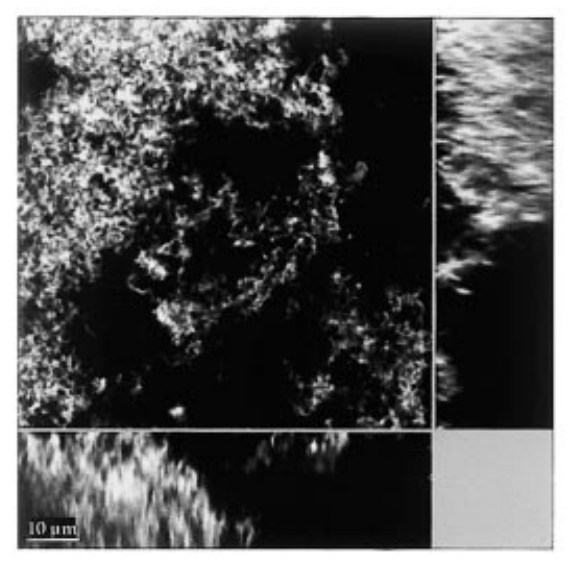

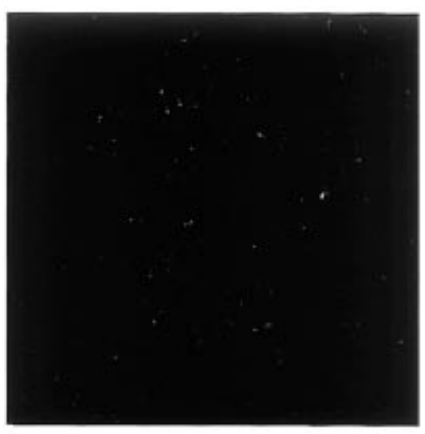
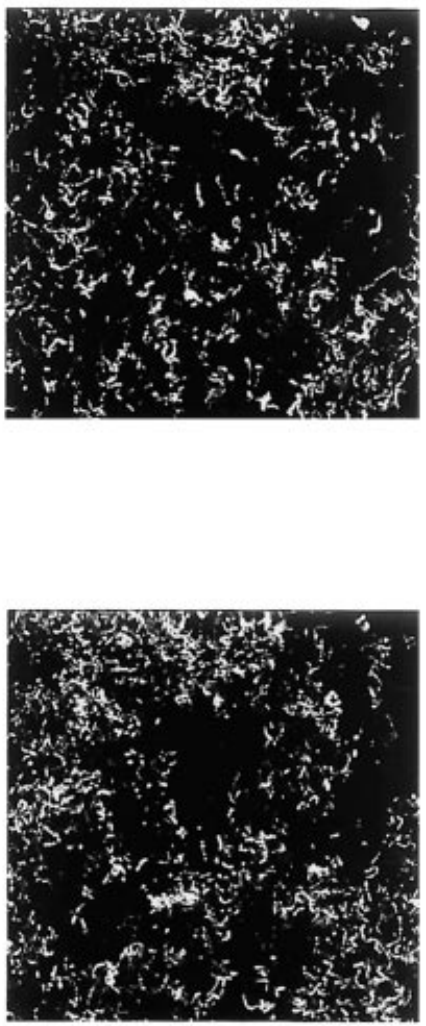

Fig. 3. Confocal micrographs of $S$. gordonii DL1(pCM18) in a biofilm shifted from anaerobic ( $\leqslant 0.025$ p.p.m. oxygen) to aerobic conditions. Green fluorescence was monitored $4 \mathrm{~min}(\mathrm{a}), 20 \mathrm{~min}$ (b), and $40 \mathrm{~min}$ (c) after a shift to aerobic medium. All scanning variables (e.g. PMT settings) were held constant over the entire observation period. The panels below and on the right side of the main frame illustrate $z x$ and $z y$ scans, respectively. Next to each confocal micrograph is shown one slice (approx. $0.3 \mu \mathrm{m}$ thick) closest to the substratum. No fluorescence was detectable at time zero. in this study demonstrate an even faster maturation of the Gfpmut3* fluorophore, which implies that this reporter protein can indeed be used effectively for assessments of up-regulated promoter activity, and that even brief exposures to oxygen should suffice for maturation of GFP synthesized under anaerobic conditions.

The actual in vivo requirements of oxygen for GFP fluorescence under limiting oxygen tensions have been determined. Maturation of the GFP fluorophore occurs at levels of oxygen as low as $0 \cdot 1$ p.p.m., whereas no fluorescence was detectable at $0 \cdot 025$ p.p.m. oxygen. This implies that the use of GFP is not restricted to aerobic bacteria and well-aerated systems-microaerophilic organisms may also be characterized using GFP. Oxygen-dependent maturation is very fast, since a fully fluorescent biofilm was obtained in less than $20 \mathrm{~min}$. A low $\mathrm{pH}$ in the environment results in low fluorescence yield, and for organisms which most often grow fermentatively it is highly important to control external $\mathrm{pH}$. 


\section{ACKNOWLEDGEMENTS}

This work was supported by a grant from the Danish Research and Development Program for Food Technology (FØTEK3) and grants from the Danish Biotechnology Program. Supply of bacterial strains and many helpful suggestions from Dr Paul Kolenbrander are highly appreciated.

\section{REFERENCES}

Andersen, J. B., Sternberg, C., Poulsen, L. K., Bjørn, S. P., Givskov M. \& Molin, S. (1998). New unstable variants of green fluorescent protein for studies of transient gene expression in bacteria. Appl Environ Microbiol 64, 2240-2246.

Bubert, A., Sokolovic, A., Chun, S.-K., Papatheodorou, L., Simm, A. \& Goebel, W. (1999). Differential expression of Listeria monocytogenes virulence genes in mammalian host cells. Mol Gen Genet 261, 323-336.

Cody, C. W., Prasher, D. C., Westler, W. M., Prendergast, F. G. \& Ward, W. W. (1993). Chemical structure of the hexapeptide chromophore of the Aequorea green-fluorescent protein. Biochemistry 32, 1212-1218.

Cook, G. M. \& Russell, J. B. (1994). The effect of extracellular pH and lactic acid on $\mathrm{pH}$ homeostasis in Lactococcus lactis and Streptococcus bovis. Curr Microbiol 28, 165-168.

Cormack, B.P., Valdivia, R. H. \& Falkow, S. (1996). FACSoptimized mutants of the green fluorescent protein (GFP). Gene 173, 33-38.

Crameri, A., Whitehorn, E. A., Tate, E. \& Stemmer, W. P. C. (1996). Improved green fluorescent protein by molecular evolution using DNA shuffling. Nat Biotechnol 14, 315-319.

Cubitt, A. B., Heim, R., Adams, S. R., Boyd, A. E., Gross, L. A. \& Tsien, R. Y. (1995). Understanding, improving and using green fluorescent proteins. Trends Biochem Sci 20, 448-455.

Delagrave, S., Hawtin, R. E., Silva, C. M., Yang, M. M. \& Youvan, D. (1995). Red-shifted excitation mutants of the green fluorescent protein. Biotechnology 13, 151-154.

Ehrig, T., O'Kane, D. J. \& Prendergast, F. G. (1995). Greenfluorescent protein mutants with altered fluorescence excitation spectra. FEBS Lett 367, 163-166.

Ehrlich, S. D., Bruand, C., Sozhamannan, S., Dabert, P., Gros, M. F., Janniere, L. \& Gruss, A. (1991). Plasmid replication and structural stability in Bacillus subtilis. Res Microbiol 142, 869-873.

Elsliger, M.-A., Wachter, R. M., Hanson, G. T., Kallio, K. \& Remington, S. J. (1999). Structural and spectral response of green fluorescent protein variants to changes in $\mathrm{pH}$. Biochemistry 38, 5296-5301.

Fernández de Palencia, P., Nieto, C., Acebo, P., Espinosa, M. \& López, P. (2000). Expression of green fluorescent protein in Lactococcus lactis. FEMS Microbiol Lett 183, 229-234.

Freitag, N. E. \& Jacobs, K. E. (1999). Examination of Listeria monocytogenes intracellular gene expression by using the green fluorescent protein of Aequorea victoria. Infect Immun 67, 1844-1852.

Geoffroy, M.-C., Guyard, C., Quatannens, B., Pavan, S., Lange, M. \& Mercenier, A. (2000). Use of green fluorescent protein to tag lactic acid bacterium strains under development as live vaccine vectors. Appl Environ Microbiol 66, 383-391.

Hansen, M. C., Palmer, R. J., Jr \& White, D. C. (2000). Flowcell culture of Porphyromonas gingivalis biofilms under anaerobic conditions. J Microbiol Methods 40, 233-239.
Heim, R. \& Tsien, R. Y. (1996). Engineering green fluorescent protein for improved brightness, longer wavelengths and fluorescence resonance energy transfer. Curr Biol 6, 178-182.

Heim, R., Prasher, D. C. \& Tsien, R. Y. (1994). Wavelength mutations and posttranslational autoxidation of green fluorescent protein. Proc Natl Acad Sci US A 91, 12501-12504.

Heim, R., Cubitt, A. B. \& Tsien, R. Y. (1995). Improved green fluorescence. Nature 373, 663-664.

Inouye, S. \& Tsuji, F. I. (1994). Evidence for redox forms of the Aequorea green fluorescent protein. FEBS Lett 351, 211-214.

Jensen, P. R. \& Hammer, K. (1998). The sequence of spacers between the consensus sequences modulates the strength of prokaryotic promoters. Appl Environ Microbiol 64, 82-87.

Kimata, Y., Iwaki, M., Lim, C. R. \& Kohno, K. (1997). A novel mutation which enhances the fluorescence of green fluorescent protein at high temperatures. Biochem Biophys Res Commun 232, 69-73.

Kolenbrander, P. E. \& London, J. (1993). Adhere today, here tomorrow: oral bacterial adherence. J Bacteriol 175, 3247-3252.

Lewis, P. J. \& Errington, J. (1996). Use of green fluorescent protein for detection of cell-specific gene expression and subcellular protein localisation during sporulation in Bacillus subtilis. Microbiology 142, 733-740.

Lewis, P. J. \& Marston, A. L. (1999). GFP vectors for controlled expression and dual labelling of protein fusions in Bacillus subtilis. Gene 227, 101-109.

Miesenböck, G., De Angelis, D. A. \& Rothman, J. E. (1998). Visualizing secretion and synaptic transmission with $\mathrm{pH}$-sensitive green fluorescent proteins. Nature 394, 192-195.

O'Sullivan, D. J. \& Klaenhammer, T. R. (1993). High- and lowcopy-number Lactococcus shuttle cloning vectors with features for clone screening. Gene 137, 227-231.

Palmer, R. J., Jr \& Caldwell, D. E. (1995). A flowcell for the study of plaque removal and regrowth. J Microbiol Methods 24, 171-182.

Patterson, G. H., Knobel, S. M., Sharif, W. D., Kain, S. R. \& Piston, D. W. (1997). Use of the green fluorescent protein and its mutants in quantitative fluorescence microscopy. Biophys J 73, 2782-2790.

Perry, D., Wondrack, L. M. \& Kuramitsu, H. K. (1983). Genetic transformation of putative cariogenic properties in Streptococcus mutans. Infect Immun 41, 722-727.

Prasher, D. C., Eckenrode, V. K., Ward, W. W., Prendergast, F. G. \& Cormier, M. J. (1992). Primary structure of the Aequorea victoria green-fluorescent protein. Gene 111, 229-233.

Reid, B. G. \& Flynn, G. C. (1997). Chromophore formation in green fluorescent protein. Biochemistry 36, 6786-6791.

Robey, R. B., Ruiz, O., Santos, A. V. P., Ma, J., Kear, F., Wang, L.-J., Li, C.-J., Bernardo, A. A. \& Arruda, J. A. L. (1998). pHdependent fluorescence of a heterologously expressed Aequorea green fluorescent protein mutant: in situ spectral characteristics and applicability to intracellular $\mathrm{pH}$ estimation. Biochemistry 37, 9894-9901.

Scott, K. P., Mercer, D. K., Glover, L. A. \& Flint, H. J. (1998). The green fluorescent protein as a visible marker for lactic acid bacteria in complex ecosystems. FEMS Microbiol Ecol 26, 219-230.

Siegumfeldt, H., Rechinger, K. B. \& Jakobsen, M. (2000). Dynamic changes of intracellular $\mathrm{pH}$ in individual lactic acid bacterium cells in response to a rapid drop in extracellular $\mathrm{pH}$. Appl Environ Microbiol 66, 2330-2335. 
Siemering, K. R., Golbik, R., Sever, R. \& Haseloff, J. (1996). Mutations that suppress the thermosensitivity of green fluorescent protein. Curr Biol 6, 1653-1663.

Ward, W. W. (1998). Biochemical and physical properties of green fluorescent protein. In Green Fluorescent Protein: Properties, Applications and Protocols, pp. 45-75. Edited by M. Chalfie \& S. Kain. New York: Wiley.
Yanisch-Perron, C., Vieira, J. \& Messing, J. (1985). Improved M13 phage cloning vectors and host strains: nucleotide sequences of the M13mp18 and pUC19 vectors. Gene 33, 103-119.

Received 2 November 2000; revised 21 December 2000; accepted 23 January 2001. 